\title{
EL DEBIDO PROCESO: \\ DEL DERECHO A LAS MÍNIMAS GARANTÍAS A LA GARANTÍA DE MÁXIMOS DERECHOS
}

Roberto González Álvarez*

\section{RESUMEN}

Las transformaciones del constitucionalismo actual comprenden la nueva noción principial del debido proceso, ella determina que no se trata más de un derecho a mínimas garantías, sino de una garantía de máximos derechos. En esta ruta se estudia el debido proceso desde sus áreas más problemáticas en el civil law desde una perspectiva comparada, presentando resultados en los que el debido proceso es componente estructural del principio de acción, lo que descansa en la conclusión de la nueva faz de esta garantía: el debido proceso proporcional.

Palabras clave: Debido proceso, acción, proporcionalidad, principios fundamentales.

\begin{abstract}
The transformations of current constitutionalism include new "principial" notion of due process, it determines that it is not more of a right to minimum guarantees, but a guarantee of maximum rights. On this route due process is studied from problem areas in civil law from a comparative perspective, presenting results that due process is a structural component of the action principle, which rests on the conclusion of the new face of this guarantee: proportional due process.
\end{abstract}

Key words: Due process, action, proportionality, fundamental principles.

\footnotetext{
Doctor en Derecho por la Pontificia Universidad Católica del Perú, grado académico obtenido con la máxima calificación que otorga esa Casa de Estudios (sobresaliente por unanimidad). Maestro en Derecho con mención en Derecho Civil y Procesal Civil por la Universidad Nacional de San Antonio Abad del Cusco. Presidente de la Sociedad Peruana de Ciencias Jurídicas SOPECJ. Candidato a Doctor en Derecho e Investigación por la Universidad Nacional de San Agustín de Arequipa (Perú). Catedrático de Derecho Procesal Civil.
} 


\section{LA Garantía Del Debido PROCESO}

No transitaré los pasajes consabidos del debido proceso, evitaré las rutas sortílegas de su naturaleza jurídica y la archiconocida narrativa de su historia que, aunque parezca una herejía decirlo, son más de los inútiles recursos explicativos que intentan justificar un "intruso" en el civil law cuando se trata de, en serio, entender y esclarecer una institución que ha sido tan manoseada como confundida, trastrocada y necesaria.

Pero decir esto no es gratuito, dado que obedece a la perspectiva integrativista trialista del derecho, que sin duda mejora la "fecundidad explicativa" del debido proceso con sus bases epistemológicas y cognitivas indispensables para canalizar la fuerza de sus medulares ideas. De tal forma, sólo cobrará vida el entendimiento que se procura sobre el debido proceso si se recuerdan las siguientes premisas ${ }^{2}$.

\section{Premisa epistemológica:}

a. El integrativismo trialista identifica la "interacción humana eficaz" como objeto del derecho, que tiene un plano ontológico (de esencia eficaz) que armoniza con un plano óntico o metódico, dando lugar a la eficacia, efectividad y eficiencia del derecho, que obran integralmente con los métodos jurísticos dikelógico (valor), normológico (norma) y sociológico (hecho), respectivamente. En esta estructura óntico-ontológica no solo se entiende el derecho mismo, sino también cualquiera de las instituciones que lo conforman.

\section{Premisas cognitivas:}

b. En el neoconstitucionalismo las normas son principios o reglas. Los principios son los derechos, sus garantías y las normas que los consagran, todos fundamentales. Los principios tienen una estructura normativa conformada por el supuesto de hecho (que fluye del derecho fundamental y que siempre es la vulneración de su contenido) y la consecuencia jurídica (que fluye de la garantía del derecho fundamental y que siempre implica un obrar negativo o positivo estatal); consecuentemente, los principios no tienen un supuesto de hecho abierto y se aplican todo o nada y no de modo parcial. A esto se suma que los contenidos del principio del debido proceso son también principios y no reglas ${ }^{3}$.

1 Cfr. VILLA, Vittorio, "Il «giusto processo» fra regole e principi", en Audiatur et altera pars. Il contradditrorio fran principio e regola, Giuffrè, Milán, 2008, p. 242.

2 Cfr. GONZÁLEZ ÁLVAREZ, Roberto, “Objeto y estructura del derecho procesal”, en Revista de Derecho Procesal, Madrid, 2009, pp. 339 y ss.; Neoprocesalismo. Teoría del proceso civil eficaz, 1a. ed., ARA Editores, 2012, pp. 41 y ss.

3 Sobre una posición contraria, en atención al artículo 111 de la Constitución italiana, cfr. FERRUA, Paolo, Il "giusto proceso", 2a ed., Zanichelli, Bolonia, 2007, pp. 25-58. 
b. Los derechos fundamentales no son sus garantías, ni viceversa.

c. El principio fundamental de acción está conformado normativo-estructuralmente por el derecho de acción y sus correlativas garantías que son, entre las más importantes, la tutela jurisdiccional y el debido proceso.

d. El debido proceso es garantía del derecho de acción, y ambos tienen sus contenidos vinculados entre sí.

e. El principio de proporcionalidad, permite delimitar los contenidos de los derechos y garantías fundamentales, cuando interactúan en un caso concreto.

\section{Problemas del debido proceso en el civil law}

¿Por qué resulta tan problemática y deficiente la asunción del debido proceso legal en el civil law? La respuesta está en (i) la deficiente traducción de su nomen iuris; (ii) la genética sistémica del debido proceso legal, que no es la del civil law; (iii) la razonabilidad y la proporcionalidad del civil law frente al due process of law; (iv) la garantía de tutela jurisdiccional y la confusión de su contenido con el del debido proceso; y (v) la falta de una teoría clara sobre el subsistema principial jurídico.

\subsection{La deficiente traducción de su nomen iuris}

El nomen iuris de origen del debido proceso legal (due process of law), que es el que se le asigna en la law of the land, guarda incorrección en tanto si bien due significa debido y process significa proceso, law no significa legal sino "derecho" en tanto se entienda por tal la ley o el acto parlamentario (act of parliament) ${ }^{4}$. Esto ha desembocado en una serie de traducciones distintas a la dominante (debido proceso legal); así, "debido proceso justo", "proceso legal justo”, “debido proceso”, etcétera.

Pero el problema no sólo es de traducción, sino del sentido mismo con que se fue forjando en la residencia de sus orígenes. Así, en el constitucionalismo de los Estados Unidos de Norteamérica se trata el procedural due process y el substative due process, es decir, el debido proceso procesal (o un due process procesal) y el debido proceso sustancial (o un due process sustancial), expresiones que son acusadas ${ }^{5}$ de equivocidad; la primera, porque es pleonástica (el sustantivo "proceso" es calificado por el adjetivo "procesal", se trata de una referencia a un "proceso procesal") y, la segunda, porque es contradictoria en sí misma (el sustantivo "proceso" es calificado por el adjetivo "sustancial", lo procesal no puede ser sustancial ni viceversa).

4 Sobre el particular, en referencia al portugués, Cfr. GAMA, Lidia; PEÑALOZA JARAMILLO, Elizabeth, O devido processo legal, Campinas, Editora de Direito, 2005, p. 19.

5 Cfr. SHAPIRO, Martin, "Il due process of law in stile americano, un modello di confusion", en Giusto processo? Introduzione di diritto fondamentali dei cittadini o creazione di canoni processuali di rango costituzionale? Scritti in onore di Giuseppe Di Federico, al cuidado de Carlo Guarnieri y Francesca Zannotti, Padua, Cedam, 2006, pp. 3 y ss. 
Haciendo a un lado el error que en su momento implicó traducir substative due process como "debido proceso sustantivo" - propio del procedimentalismo que, consecuentemente, dio espacio a un "debido proceso adjetivo"-; en el procesalismo actual del civil law, las críticas referidas - que provienen del common law-, resultan poco rigurosas, pues hasta cierto punto devienen altamente subjetivas y, en todo caso, privatistas; la primera, apela a una asepsia semántica que en muchos casos resulta inversa a la utilidad de su empleo, pues en el mundo jurídico procesal identificar, v.gr. el "proceso procesal", tiene sentido altamente explicativo; y la segunda, no se ajusta a la teoría jurídica actual que contempla plenamente normas y derechos procesales materiales, es más, teniendo en sus dominios la teoría de la "relatividad contextual" entre normas formales y sustantivas; de igual modo, no se ajusta al contexto procesal actual en el que la diferenciación privatista entre "fondo" y "forma" resulta lugar común de muchos problemas ${ }^{7}$ en el mundo procesal, de los que éste solo se libra si conjura la conceptuación contractualista del proceso y entiende que en éste guarda corrección lo subjetivo material y lo subjetivo procesal.

\subsection{La genética del debido proceso legal no es la del derecho procesal del civil law}

Cuando se atribuyó al Estado la exclusividad del reparto ordenancista autoritario (impartición de justicia), estatuyendo luego la tipicidad de los delitos y, consecuentemente, la aplicación de las penas bajo el respeto de esa exclusividad, se aseguró la repartición ordenancista autoritaria solamente por los tribunales, en una clara acentuación del equilibrio de poderes ${ }^{8}$ y de la necesidad de un método que permita a los tribunales aplicar las penas: el proceso.

Con lo indicado se hizo evidente la necesidad de asegurar (rectius, garantizar) al justiciable no solo la aplicación de la pena previo proceso, sino el respeto de las reglas preestablecidas para la realización de ese proceso, entonces, la diversidad de esas reglas se abrió espacio en los ordenamientos estatales, no sin dejar de mostrar sus precedentes más distinguidos en antiguos ordenamientos, v.gr., la Biblia (Deuteronomio, 16: 18 ss.; San Juan, 7: 51).

Este punto de partida no solo indica que la necesidad de corrección o regularidad (legalidad) de la aplicación de las reglas del proceso, que por esa corrección

6 Cfr. FERRAJOLI, Luigi, Principia Iuris. Teoría del derecho y de la democracia, traducción de Perfecto Andrés Ibáñez; Luis Prieto Sanchís; Marina Gascón Abellán; Alfonso Ruiz Miguel; Juan Carlos Bayón, Trotta, Madrid, 2011, v. I, p. 835.

7 Cfr. IBÁÑEZ FROCHAM, Manuel, La jurisdicción, Astrea, Buenos Aires, 1972, p. 29; NIEVA FENOLL, Jordi, Jurisdicción y proceso, Marcial Pons, Madrid, 2009, p. 16 s.

8 Cfr. SILVEIRA, Paulo Fernando, Devido processo legal, Belo Horizonte, Del Rey, 2001, pp. 49 y ss. 
se llamaría "debido", surgió apuntando al proceso penal ${ }^{9}$ o que la referida corrección procesal se impuso como una garantía asignada a quien se le imputaba una comisión delictual, sino inicia una serie de errores como entender la garantía de corrección del proceso como tutela jurisdiccional, o peor, el proceso como garantía, o peor aún, la tutela jurisdiccional y el debido proceso como si fuesen lo mismo o, encareciendo aún más esa oposición a lo bueno, diversas categorías, clases o específicas formas de debido proceso. Tal vez en esto último el tenue contacto del constitucionalismo con el procesalismo ocasionó que en algún sector del pensamiento procesal el debido proceso podía entenderse como contenido de la tutela jurisdiccional, puesto que al fin y al cabo ésta se malentiende como una situación jurídica ${ }^{10}$-claro está, en la mejor de las peores acepciones de tutela jurisdiccional trocada por tutela procesal, sin afirmar siquiera una clara y válida diferencia-, que abarca todo cuanto sitúa como derechos y obligaciones en el entorno del sujeto de derecho. En verdad, estos errores son consecuencia del abordaje constitucional por lo procesal cuando, tratándose del debido proceso, la exigencia es inversa.

La historia del debido proceso legal ${ }^{11}$ es, sin duda, harto tratada y de reiterada presencia en la mayoría de estudios procesales, de manera que nada aportaría repetirla aquí, por lo que si algo corresponde aclarar es que esa historia es la del constitucionalismo, o mejor, de los principios fundamentales en el constitucionalismo y, por tanto, más que interesar como precedente del debido proceso en la perspectiva procesal, importa como precedente del subsistema principial de la Constitución, porque su decurso no aporta ni esclarece por sí mismo la corrección en el entendimiento del due process of law, sino como ruta de arribo a un crucial momento, que no deja de ser histórico, en que la principiología jurídica asume un rol medular (neoconstitucional) y, en ello, hay mucho que decir sobre el debido proceso, más aún, si de él también mana la composición integrativista trialista del derecho. Lo dicho no exime de reparar algunos puntos históricos del debido proceso que hacen que cuando se intentan alinear con la ruta del civil

$9 \quad$ Sobre el due process of law en el proceso federal de los Estados Unidos de Norteamérica Cfr. ESPARZA LEIBAR, Iñaki, El principio del proceso debido, Barcelona, Bosch, 1995, pp. 67 y ss.

10 Cfr. MONROY, MONROY GÁlVEZ, Juan Francisco, "Artículo 139.3", en La Constitución comentada. Análisis artículo por artículo, Lima, Gaceta Jurídica, 2005, t. I, p. 498.

11 Sobre el origen e historia del debido proceso Cfr. LINARES, Juan Francisco, Razonabilidad de las leyes - El "debido proceso" como garantía innominada en la Constitución argentina, Buenos Aires, 2a . ed., Astrea, 1989, pp. 15 y ss.; DE BERNARDIS, Luis Marcelo, La garantía procesal del debido proceso, Lima, Cultural Cuzco, 1995, pp. 141 ss.; Silveira, Paulo Fernando, Op. cit., pp. 3 ss.; GONZÁLEZ LINARES, Nerio, Ensayos de derecho procesal civil, IPIJ, Cusco, 2003, pp. 115 ss.; Derecho procesal civil. Teoría del proceso civil, Universidad Andina del Cusco, Cusco, 2005, pp. 157 ss.; GAma, Lidia Elizabeth Peñaloza Jaramillo, Op. cit., pp. 39 ss.; CAStro, Carlos Roberto Siqueira, O devido processo legal e os princípios da razoabilidade e da proporcionalidade, Rio de Janeiro, Forense, 2005, pp. 5 y ss. 
law trastabillen, sobre todo con los institutos propios de este sistema, cuando es recibido en los países que comprende (Alemania ${ }^{12}$, Italia ${ }^{13}$, España ${ }^{14}$, Argentina ${ }^{15}$, Brasil $^{16}$, etcétera).

El due process, sin adjetivo que lo califique, surge en Inglaterra con una función legislativa y judicial, estableciendo la sujeción del monarca a las leyes generales adoptadas del Parlamento y aplicadas con un judicial proceeding ${ }^{17}$, lo que significa la (pre)existencia de un procedimiento judicial y que éste frene la arbitrariedad del Ejecutivo. Ese mismo sentido fue el que tuvo en los Estados Unidos de Norteamérica, aunque no con claridad que perdurara, sobre todo porque el desarrollo de la garantía del juzgamiento sobre la base de leyes generales no se dio bajo el rubro del due process, sino bajo la prescripción del valor universal de las leyes, que el Bill of attainder clause contenía, y del principio de la separación de poderes.

Luego, el due process fue desplazado por el procedural due process, enfocando su ámbito de acción a la regularidad de procedimientos administrativos y procesos judiciales, y aquí es donde la jurisprudencia tejió los músculos fundamentales del procedural due process, en medio de los problemas del federalismo ${ }^{18}$, que condujeron a la Corte Suprema a interpretar de la due process clause de la XIV Enmienda, tanto derechos procesales como derechos sustanciales de la Carta de Derechos (Bill of Rights), posicionándose así el substantive due process.

12 Sobre el due process of law en el derecho procesal penal alemán Cfr. Esparza Leibar, Iñaki, Op. cit., pp. 117 y ss.

13 Cfr. ROTA, Fabio, "I principi costituzionali", en DENTI, Vittorio, La giustizia civile. Lezioni introduttive, Bologna, Il Mulino, 1989, pp. 77 ss.; COMOGLIO, Luigi Paolo, Etica e tecnica del "giusto processo", Turín, Giappichelli, 2004, pp. 225 y ss.; ZANNOTTI, Francesca, "La costituzionalizzazione dei principi del guisto processo nel dibattito parlamentare", en Giusto processo? Introduzione di diritto fondamentali dei cittadini o creazione di canoni processuali di rango costituzionale? Scritti in onore di Giuseppe Di Federico, al cuidado de Carlo Guarnieri y Francesca Zannotti, Padua, Cedam, 2006, pp. 31 ss.; PEDERZOLI, Patrizia, "Corte costituzionale e parlamento, il confronto sul giusto processo", en Giusto processo?... Op. cit., pp. 115 y ss.; NICOLİ, Antonio, «L'attuazione del principio del giusto processo tra costituzione e legge ordinaria", en Giusto processo?... Op. cit., pp. 139 y ss.; SAPIGNOLI, Michele, "Giusto processo e cultura giuridica interna, i risultati di alcuni studi empirici”, en Giusto processo?... Op. cit., pp. 185 y ss.

14 Sobre el reconocimiento legal y jurisprudencial del due process of law en España Cfr. ESPARZA LEIBAR, Iñaki, Op. cit., pp. 161 y ss.

15 Cfr. LINARES, Juan Francisco, Op. cit., pp. 159 y ss.; MORELLO, Augusto Mario, 1994, El proceso justo, Buenos Aires, Hammurabi.

16 Cfr. SILVEIRA, Paulo Fernando, Op. cit., pp. 246 y ss.; COMOGLIO, Luigi Paolo, Op. cit., pp. 208 ss.; CASTRO, Carlos Roberto Siqueira, Op. cit., pp. 285 y ss.; Gama, Lidia Elizabeth Peñaloza Jaramillo, Op. cit., pp. 53 y ss.

17 Cfr. SHAPIRO, Martin, Op. cit., p. 4.

18 Ibídem.,5 ss. 
La construcción del substantive due process se erige, por un lado, en la razonabilidad ${ }^{19}$ que justifica la intervención estatal en la vida, la libertad y la propiedad (según la idea de que nadie puede ser privado de la vida, libertad o propiedad sin due process of law, de manera que si hay ese due process y mediante él se justifica la razonabilidad de la intervención de un derecho -sea de la vida, libertad o propiedad-, que no es absoluto, la restricción estatal implicada es permitida, o aún mejor, es legítima), superando el control de constitucionalidad; y, por otro lado, en la razonabilidad gradual (que va de la razonabilidad a la razonabilidad intensa), en la intervención de los derechos fundamentales específicos del Bill of Rights colisionados entre sí.

Siendo así, el procedural due process implica un control ${ }^{20}$ de constitucionalidad ligero o suave, pues no prohíbe al actuar estatal, solo determina si éste está encausado en la corrección procesal y si amerita una sanción; en cambio, el substantive due process importa casos judiciales sobre derechos (rights cases), por tanto un control de constitucionalidad complejo, un examen jurisdiccional de legitimidad orientada por una política de equilibrio, de equidad, es decir, por un proceso equitativo e imparcial ${ }^{21}$.

Interesa reparar, de la diferenciación precedente, que el substantive due process remite a los balancing cases, es decir, a los mal llamados ${ }^{22}$ casos difíciles $^{23}$, o a aquellos en los que la interpretación y aplicación normativa es por ponderación ${ }^{24}$.

Como se puede ver la historia del due process es la historia del judicial review, a cargo de cortes ordinarias (regular courts), no es la historia del control kelseniano de constitucionalidad frente a la que, aun en sistemas duales (difuso y concentrado), no deja de ser historia ajena, con consecuencias tan marcadas de incompatibilidad como las lecturas tan disímiles de la razonabilidad, la oposición entre el desarrollo de la corrección procesal a través de principios procesales en el civil law y mediante control de constitucionalidad en el common law, en fin, incompatibilidades propias entre common law y civil law.

19 Cfr. CASTRO, Carlos Roberto Siqueira, Op. cit., pp. 141 y ss.; TUCCI, Rogério Lauria y TUCCI, José Rogério Cruz, Devido processo legal e tutela jurisdicional, São Paulo, RT., 1993, pp. 18 y s.

20 Cfr. ALMAGRO NOSETE, José, Constitución y proceso, Bosch, Barcelona. 1984, pp. 105 y ss.

${ }^{21}$ Sobre debido proceso e imparcialidad del juez Cfr. GUARNIERI, Carlo, "Divisione del potere, giusto processo e separazione delle carriere", en Giusto processo? Introduzione di diritto fondamentali dei cittadini o creazione di canoni processuali di rango costituzionale? Scritti in onore di Giuseppe Di Federico, al cuidado de Carlo Guarnieri y Francesca Zannotti, Padua, Cedam, 2006, pp. 86 y ss.

22 Cfr. GONZÁlEZ ÁlVAREZ, Roberto, Neoprocesalismo... Op. cit., c. III, sc. I, 10.

${ }^{23}$ Sobre casos difíciles Cfr. DWORKIN, Ronald, Los derechos en serio, traducción de Marta Guastavino, Ariel, Barcelona, 1984, pp. 158; MARTÍNEZ ZORRILLA, Metodología jurídica y argumentación, Madrid, Marcial Pons, 2010, pp. 25 y ss.

24 Cfr. GONZÁlEZ ÁLVAREZ, Roberto, Neoprocesalismo... Op. cit., c. III, sc. I, 7. 
El pragmatismo y "seudológica" del common law norteamericano salta a la vista si se trata del due process of law expuesto en el civil law. No hay mayor demostración de la debilidad de un falso "facilismo mental" como hábito judicial del common law norteamericano que el que se expone magnánimamente con el debido proceso legal en el civil law. Evidentemente, la implantación de una institución del common law en el civil law no solo distorsiona los espacios con que colinda en este último, sino presenta a aquel sistema faltando a su real importancia y dimensión, de ahí que expresiones como "seudológica" o "falso facilismo mental" cobran algún sentido, y solo en ese escenario (civil law), sobre el norteamericanísimo debido proceso.

Pero ello no solo se ve desde ese ángulo, sino también desde otro igual de peculiar; pues muchas veces se ha podido constatar la autoatribuida superioridad del common law norteamericano cuando algunos de sus cultores ${ }^{25}$ lo comparan con el civil law. En esta penosa tarea se exponen rabiosas y encendidas críticas al estilo y a la sintaxis del discurso del civil law, sobre todo en italiano y español, con soberbias, prejuiciosas y despectivas sentencias que, es fácil advertirlo, son consecuencia del desconocimiento de sus exigencias epistemológicas, de sus conjugaciones y semántica, tan llanas algunas veces y tan angulares otras, pero sin duda tan válidas, útiles y hermosas como las estructuras del idioma de CERVANTES o del idioma de Alighieri. La diferencia ${ }^{26}$, es que en el civil law se piensa bajo esos parámetros idiomáticos, y no con el agazapado "facilismo" del inglés que así se logra divisar desde su orilla.

La diferencia es, pues, cultural en todo el sentido de la palabra. Entonces, no es raro que la importación del debido proceso legal, o peor, de lo que se pudo traducir del due process of law, no transite más allá de una necesidad que muchos dirán "esnobista”, por no decir de moda o en boga, y que se reduce a ese fenómeno, es decir, a emplear una infeliz traducción del pensamiento e idioma extranjeros, cuando en el pensamiento e idioma propios hay términos tan felices (v.gr., proporcionalidad, legalidad, eficiencia) y amplios para significar lo que se quiere con la indebida y trastabillante importación.

Tal vez la culpa circule desde el embobamiento de afortunados pasantes de universidades norteamericanas (que retornan a casa a iluminar el recargado conceptualismo, del entretejido discurso del civil law, con la luz del análisis económico

25 Cfr. CAPPAlLI, Richard B., "Procedimiento civil comprado, Estados Unidos, Chile y Sudamerica", en Revista Chilena de Derecho, v. 19, n 2, 1992, pp. 203-275; "At the point of decision, the common law's advantage over the civil law", en Temple International and Comparative Law Journal, v. 12, 1998, pp. 87 y ss.

26 Sobre la diferencia entre los procesos civiles norteamericano y sudamericanos Cfr. SILVESTRI, Elisabetta, "Il profilo comparatístico", en DENTI, Vittorio, La giustizia civile. Lezioni introduttive, Bologna, Il Mulino, 1989, pp. 45 y ss.; CAPPALLI, Richard B., Op. cit., pp. 203 y ss.; TARUFFO, Michele, Sobre las fronteras. Escritos sobre la justicia civil. Traducción de Beatriz Quintero, Bogotá, Temis, 2006, pp. 57 y ss.; 2008; GARAPON, Antoine y PAPADOPOULOS, Loannis, Juzgar en Estados Unidos y en Francia. Cultura jurídica francesa y common law. Traducción de Viviana Díaz Perilla, Bogotá, Legis, 2008. 
del derecho o de una inteligencia tan natural como sencilla y útil en la solución de los problemas jurídicos, con que pragmáticas voces les alimentaron), pasando por la sobreactuada cultura de los que escriben en español y citan (escribiendo las citas) en todos los idiomas que les sean posibles, hasta llegar a algunos profesores "prácticos", por llamarlos de alguna manera, que rehúyen el estudio comparado intrasistémico de las instituciones y problemas jurídicos y que no les cuesta mucho identificarlo con la pesadilla del "pelo teórico", y en consecuencia, caen fácilmente seducidos para endiosar el "sueño" del common law.

Pero, cómo ver una solución a esto si ni el embobamiento del estudiante barnizado con el logo de una universidad norteamericana, ni la apariencia de erudición del jurista alucinado ni el pragmatismo del profesor improvisado pueden significar un cambio cuando se corrijan, si el problema radica en la brutal imposición de modelos jurídicos norteamericanos, en el resto de países, desde toda conexión, comercial o no, con ellos. Y esto no queda ahí, se traduce en el brazo fuerte de una inderrotable globalización que no cede en obligarnos a hablar en inglés y, algunos dirán por qué no, a pensar en inglés.

Lo dicho no implica ningún mal presagio ni catastrofismo, porque simplemente no tienen razón para existir, pues el optimismo con que se debe enfrentar la globalización también hace ver que la exposición del civil law propicia la fuerza de su influencia y, claro está, de su perfeccionamiento. La clave está en el celo puesto en la identidad del sistema, no por chauvinismo, sino porque su fina máquina rechina con piezas que no calzan en su potencia. Esto no quiere ni podría intentar señalar rivalidad entre sistemas ni, mucho menos, la superioridad de uno sobre otro, eso sería caer en la torpeza que se critica, solo se busca evitar o reparar las alteraciones del sistema que se maneja por implantaciones que perturban la fluidez sistémica, con consecuencias de incompatibilidad institucional evidentes.

Finalmente, si algo debe quedar claro es que esa incompatibilidad genética del debido proceso en el civil law, solo se logra ver con anteojos procesales; pero, si el lente constitucional asoma su presencia y con él se logra ver que el debido proceso, ante todo, es componente principial del derecho, pues es garantía del derecho de acción, la genética fundamental será una sola y absolutamente compatible con el civil law, en la medida en que el constitucionalismo actual, afirmado con un pie en el common law y el otro en el civil law, no reconoce los principios jurídicos (fundamentales) sin su universalidad.

\subsection{La razonabilidad y la proporcionalidad del civil law frente al due process of law}

Si se habla de debido proceso en sentido amplio, que es preferible ${ }^{27}$ a "debido proceso sustantivo", porque no arrastra las distorsiones semánticas ni sistémicas del

27 Cfr. GONZÁlEZ ÁLVAREZ, Roberto, Neoprocesalismo... Op. cit., c. III, sc. II, 4. 
substantive due process, se entiende la garantía de corrección de formas, por las que discurren los contenidos democrático-constitucionales, superando en espectro garantista a las vinculaciones de la acción como derecho a la justicia, puesto que su contenido abarca los procedimientos legislativo, administrativo e intra privatos, que vinculan al debido proceso como garantía también de otros derechos (v.gr., derechos a leyes válidas y de petición), es decir, no es garantía exclusiva del derecho de acción, sino de aquellos que componen el derecho a la participación democrática; y si se habla de debido proceso en sentido estricto, que es preferible a "debido proceso procesal" (o peor, adjetivo), porque tiene mayor articulación sistémica, se entiende la garantía vinculada exclusivamente por el derecho de acción como derecho al proceso.

Si esto es así, la proporcionalidad ${ }^{28}$ cumple en el civil law la función de control constitucional que ejerce la razonabilidad en la ponderación ${ }^{29}$ del common law, y la razonabilidad, en el civil law, no es sino un criterio de interpretación y aplicación que discurre en el contenido del principio de proporcionalidad, el cual, no genera en la jurisprudencia los problemas que sí propicia la razonabilidad del substantive due process.

\subsection{La garantía de tutela jurisdiccional y la confusión de su contenido con el del debido proceso}

El destino común al que se enfrenta una institución importada es, o bien su deslegitimación en el ámbito en que es recibida, o bien su reconstrucción con nociones que son parte del equipaje importado y vernáculas, claro está, no sin sufrir las consecuencias de la hibridación. La primera consecuencia ocurre, o debe ocurrir, con el substantive due process pues no es empleado en la tutela de los principios fundamentales, esa labor la cumple el principio de proporcionalidad; y la segunda consecuencia, ocurre con el procedural due process, en tanto al no saberse cómo entenderlo por sí mismo, se apeló a divisarlo siempre en relación a otros derechos fundamentales, particularmente en relación al "derecho a la tutela jurisdiccional efectiva", del que se dijo era continente del debido proceso procesal. Situación generada por la jurisprudencia del artículo 24.1 de la Constitución española. No es raro, entonces, que también desde fuera se diga ${ }^{30}$ que el derecho consagrado en el referido numeral es el correlato hispánico del debido proceso, y ello no se diferencia

28 Cfr. Ibidem.,c. III, sc. I.

29 Cfr. BERNAL PULIDO, Carlos, "Democracia y derechos, problemas de fundamentación del constitucionalismo", en El canon neoconstitucional, CARBONELL, Miguel y GARCÍA JARAMILLO, Leonardo (Editores), Bogotá, Universidad Externado de Colombia, 2010, pp. 7 y Ss.

30 Cfr. BERNAL PULIDO, Carlos, El derecho de los derechos, Bogotá, Universidad Externado de Colombia, 2005, pp. 337. 
mucho de la afirmación de comprensión del debido proceso en el "derecho" a la tutela jurisdiccional efectiva.

Lo cierto es que cuando se forjó el derecho a la tutela jurisdiccional efectiva se trató de consagra el derecho de acción, cosa curiosa, sin mencionarlo o acudiendo a algo que se pudiera entender por él, de manera que queda claro que el contenido que se le empezó a asignar desde la jurisprudencia es el que le corresponde al derecho de acción. Ahora, la retorcida confusión entre derechos, principios y garantías, que descansa en la ambigüedad de la antesala al neoconstitucionalismo, permitió que en ese contenido del derecho a la tutela jurisdiccional efectiva también se comprendieran garantías del derecho que en realidad se debió positivizar, la acción. Esto señala que ese contenido cada vez más creciente no tenía un punto de diferenciación del contenido que se fue asignando al debido proceso.

El debido proceso, considerado también como derecho, transitó con un contenido cada vez más abultado y entremezclado con el contenido del derecho a la tutela jurisdiccional efectiva, al punto tal que cuesta esclarecer cuál contenido pertenece a cada uno de estos "derechos". De manera que, la vulneración de cualquier garantía de la acción, pareciera implicar también la del debido proceso. Para atestiguar esto basta una breve mirada a la jurisprudencia constitucional española ${ }^{31} \mathrm{y}$ a la influenciada por ella.

Es más, en cualquier ámbito del civil law no existe uniformidad ${ }^{32}$ sobre los principios que lo conforman, ni una real dimensión de su contenido, sea en una perspectiva amplia ${ }^{33}$ (comprendiendo los medios y recursos concernientes a los principios de justicia, igualdad, contradictorio, amplia defensa, universalidad de la jurisdicción y seguridad jurídica), intermedia ${ }^{34}$ (abarcando todos los principios de los actos procesales, nulidades, prueba, sentencia y recursos) o restringida ${ }^{35}$ (como supeditación del proceso a las normas jurídicas).

Esta situación se esclarece con el neoprocesalismo, mejor aún, con el integrativismo trialista vertido a él, porque solo así se entiende con claridad que el derecho de acción no es sino el derecho a la justicia, a la función jurisdiccional y al proceso, y que en cada uno de estos ámbitos el contenido de la acción no es el mismo, por lo que las garantías que vinculan tampoco lo serán; de manera que los derechos

\footnotetext{
31 Cfr. ESPARZA LEIBAR, Iñaki, Op. cit., pp. 178 y ss.

32 Cfr. GAMA, Lidia Elizabeth Peñaloza Jaramillo, Op. cit., p. 30.

33 Cfr. HOFFMANN, Susy Gomes, "O princípio do devido processo legal e sua aplicação ao direito tributário", en Revista da Faculdade de Direito de Pinhal, Espírito Santo do Pinhal, 1998, p. 14.

34 Cfr. PORTANOVA, Rui, Princípios do processo civil, Porto Alegre, Livraria do Advogado, 1997, pp. 145 y ss.

35 Cfr. BERMUDES, Sérgio, Introdução ao direito processual civil, Rio de Janeiro, Forense, 1996, p. 109.
} 
contenidos en la efectividad de la acción (la acción como derecho a la función jurisdiccional), serán siempre estructural y normativamente vinculantes de las garantías contenidas en la tutela jurisdiccional, y lo propio ocurrirá con los derechos contenidos en la eficiencia de la acción (la acción como derecho al proceso), frente a las garantías contenidas en el debido proceso (en sentido estricto).

Ahora, esto en nada puede afectar el orden integrativista trialista del derecho de acción, que significa que sus dimensiones son interactuantes, es decir, se trata de un único derecho con una composición trialista que actúa en forma integral, lo que permite entender que si bien un derecho contenido en la efectividad del derecho de acción enlaza una garantía contenida en la tutela jurisdiccional, no significa que excluya otras garantías que no sean de la tutela jurisdiccional, es decir, no significa que no pueda guardar vinculación estructural normativa con las garantías contenidas en el debido proceso. Esto es cierto en la medida en que los principios técnicos, o de eficiencia, son desprendimientos, por sus fundamentos no por derivación, de los principios de efectividad, y éstos, a su turno, de los de eficacia.

\subsection{La falta de una teoría clara sobre el subsistema principial jurídico}

Si algún sector del entendimiento del debido proceso causa terribles estragos en la viabilidad de su recorrido en el civil law, es el de su naturaleza jurídica, es decir, si algo se sabe sobre el debido proceso es su historia y contenido, de manera que la mención de su ser casi siempre es por lo que contiene y no por lo que es. Siendo así, se entiende la institucionalización del debido proceso, en el derecho internacional y en el derecho interno, en normas supranacionales y constitucionales que no refieren el nomen iuris debido proceso, sino indican su contenido.

La institucionalización del debido proceso como derecho humano en el ámbito internacional, es una clara muestra de que se entiende el debido proceso por su contenido y no propiamente por lo que es; así, los contenidos que se le reconocen y que son los que aparecen de los textos normativos, son los que dan pauta para identificarlo como derecho humano. Ahora, esta situación se repite cuando en el ámbito del derecho interno se institucionaliza como derecho fundamental, existiendo algunos casos, sobre todo en las Constituciones menos antiguas, en que se emplea el nomen iuris debido proceso como derecho; pero, es de rescatar que en algunos casos no se determina el debido proceso como derecho. Un ejemplo de ello aparece de la redacción del artículo 139 de la Constitución peruana.

Si esto es así, la doctrina y jurisprudencia no se dejaron esperar para irreflexivamente etiquetar el debido proceso como "derecho"36, en un inmenso maremágnum entre principio, derecho, garantía, criterio, etcétera, al punto tal que el debido

36 Cfr. Corte Constitucional (Colombia), sentencia T-751A de 1999, criterio suscrito por el Tribunal Constitucional (Perú), 1209-2006-PA/TC (F. J. 28). 
proceso en una común aprehensión es principio, pero no en el contexto neoconstitucional, sino en el tradicional sesgo de los principios generales del derecho o de esos preceptos que impulsan el sistema jurídico, sin poder reconocerse en ellos condición normativa alguna, o peor, es un derecho, y como los derechos fundamentales, en las más viejas tradiciones, son también garantías, el debido proceso es un derecho-garantía; por lo que, no faltaron, entonces, quienes afirmen que el debido proceso es principio, derecho y garantía.

Ante tanta oscuridad y ambigüedad, que no amerita mayor extensión, el arribo del neoconstitucionalismo, y con él la perspectiva de los principios como normas, es la piedra miliar que indica un nuevo punto de partida en el estudio y manejo de los principios, de manera que desde la perspectiva integrativista trialista, se puede advertir la estructura normativa principial, como la composición estructural normativa que permite la lectura del supuesto fáctico en la violación de un derecho fundamental, es decir, en la positivización de un derecho fundamental; y la lectura de la consecuencia jurídica, en la prescripción normativa de la correlativa garantía de ese derecho.

Los principios son derechos, sus correlativas garantías y las normas que los consagran, todos fundamentales, esto significa que la conjunción estructural de un derecho con sus correlativas garantías es un principio; entonces, tanto derechos como sus correlativas garantías pueden denominarse principios indistintamente, porque su naturaleza lo permite dada su materialidad, o mejor, su fundamentalidad, pero no se puede denominar derecho lo que es garantía ni viceversa, porque su propia naturaleza también se asegura de ello.

Siendo así, el debido proceso es garantía del derecho de participación democrática, el cual, no deja de evidenciar en su contenido la participación del derecho de acción. Esto hace que el debido proceso, como garantía del derecho de acción, tenga (i) una perspectiva amplia, porque sobrepasa los contenidos del derecho de acción y se proyecta a toda otra manifestación del derecho de participación democrática, erigiéndose en núcleo del Estado democrático de derecho; y también (ii) una perspectiva estricta, que concentra su contenido en relación a la acción como derecho de acceso al proceso, es decir, es la perspectiva procesal fundamental (de ahí lo de estricto) que revela desde su contenido.

Pero no todo es tan llano como se quisiera, el arraigamiento mental a un debido proceso, del que nada clara resulta su naturaleza, es muy fuerte, tanto que aún cuando se reconozcan y profesen los mayores postulados del neoconstitucionalismo, que permiten un posicionamiento firme sobre el rango normativo de los principios, cuando se trata de estudiar, interpretar y aplicar el contenido del debido proceso, pareciera que ello no cala en modo alguno; de manera que, la doctrina autoral y jurisprudencial no cesa en confundir las garantías con los derechos, con una innegable consecuencia de ausencia de rigor semántico. 


\section{3. (IN)DISPENSABILIDAD DEL DEBIDO PROCESO EN EL CIVIL LAW}

¿Es (in)dispensable el debido proceso legal en el civil law? La respuesta es un asunto de contenidos, pues si bien la garantía de tutela jurisdiccional tiene indefinida la colindancia de su contenido con el del debido proceso y si bien el debido proceso se identifica, define y entiende no por lo que es, sino por lo que contiene, esos contenidos no son nada nuevos en el civil law; de manera que, en la imaginación de que desapareciera la denominación "debido proceso" de la faz procesal, los contenidos continuarían siendo invocados con tanta necesidad y consecuencia como si el debido proceso estuviera presente, seguramente los contenidos migrarían a un continente mayor que en este caso sería la garantía de jurisdicción; y el ámbito de razonabilidad, que discurre por el debido proceso (sustantivo o material), sería tranquilamente asumido por la garantía de proporcionalidad. Estoy seguro que la semántica del civil law hallaría paz en algunos de sus rincones, no sin el beneficio de la castidad sistémica que ello implicaría.

Pero, los tiempos cambian y con ellos también los pensamientos, de manera que no se puede dejar de reconocer que, en la vida jurídica actual, el debido proceso está transfundido del linaje romano-germánico, hablan de ello su consagración en la normatividad supranacional ${ }^{37}$, su intenso transitar por la casuística ${ }^{38}$, su absorción por la cognición integrativista-trialista y en ella, he aquí lo medular, su configuración neoprocesal, con consecuencias normativas, jurisprudenciales y doctrinales muy acentuadas en su utilidad.

En consecuencia, el debido proceso es dispensable en su vieja acepción procesal (que en el civil law se define por lo que contiene o por lo que no es, pero nunca por lo que es, y en el common law se define como control de constitucionalidad desde la razonabilidad -substantive due process); y resulta indispensable en su nueva y paradigmática estructuración neoconstitucional, como garantía del derecho de acción, que se manifiesta en la estructura integrativista trialista del derecho (i) en vinculación amplia con la acción entendida como derecho a la justicia, sobrepasándola puesto que asiste al enlace estructural normativo de todo derecho contenido en el de participación democrática; y (ii) en vinculación estricta con la acción entendida como derecho al proceso, delimitando su contenido según la naturaleza de los derechos contenidos en el derecho de acción.

Preciso la idea, el substantive due process es incoherente en el civil law, por la presencia del principio de proporcionalidad, que siendo nativo del civil law no

37 Cfr. ROTA, Fabio, Op. cit., pp. 73 y ss.; TROCKER, Nicolò, "Il nuovo articolo 111 della costituzione e il "giusto processo" in materia civile, profili generali", en Rivista Trimestrale di Diritto e Procedura Civile, Milán, Giuffrè, año Lv, n. 2, 2001, pp. 386 y ss.; COMOGLIO, Luigi Paolo, Op. cit., pp. 97 y ss.

38 Cfr. GOZAÍNI, Osvaldo Alfredo, Derecho procesal constitucional. El debido proceso, Buenos Aires, Rubinzal-Culzoni, 2004, pp. 69 y ss. 
puede ser desplazado por una extraña institución, más aún, porque sus piezas se articulan plena y naturalmente con las demás de su familia; en cambio, el procedural due process debe reconceptualizarse en el civil law al calor del neoprocesalismo. Consecuentemente, es preferible la configuración del debido proceso en sentido amplio y en sentido estricto, entendiendo por el primero el debido proceso como garantía de la eficacia de la acción y, por el segundo, el debido proceso como garantía de la eficiencia de la acción. En suma, el debido proceso es tal sin más, lo que significa que no hay debido proceso sustancial en el sentido del substantive due process, sino debido proceso que se puede manifestar en sentido amplio, en tanto garantía intra/extraproceso correlativa del derecho de acción y de todo otro derecho manifestación del derecho de participación democrática, o en sentido estricto, en tanto garantía intraproceso.

¿Cómo homologar el debido proceso legal en el civil law? (Re)Construyéndolo desde el derecho constitucional, propiamente desde el subsistema principial de la Constitución, es decir, desde la perspectiva integrativista-trialista-neoconstitucional del derecho procesal, lo que permite entender que el principio de acción está estructurado normativamente por el derecho de acción y sus garantías correlativas, una de éstas es la del debido proceso, por tanto, el debido proceso no es un derecho, sino una garantía, tiene un contenido principial y tiene una composición eficaz, que la proyecta en un sentido amplio, y una composición eficiente, que la proyecta en un sentido estricto.

\section{LA garantía del derecho de PARTICIPACIÓN DEMOCRÁTICA: EL DEBIDO PROCESO (EN SENTIDO AMPLIO)}

La garantía de debido proceso (en sentido amplio) sobrepasa las extensiones de los contenidos del derecho de acción; así, sus vinculaciones con los derechos a leyes proporcionales, de defensa y de petición (ante autoridad pública o ente privado) también son patentes, de manera que no es extraño que los debidos procesos legislativo, administrativo o inter privatos sean expresiones claras del debido proceso fuera del contexto procesal.

Entonces, ¿por qué ajustar su denominación (debido "proceso") fuera de lo "procesal"? Porque la institucionalidad del debido proceso en el contexto extraprocesal obedece a la sustantividad (rectius, fundamentalidad) forjada en su origen y devenir históricos (desde sus contenidos), que en la actualidad se basa en la democracia constitucional (en el contenido del derecho de participación democrática) y en el principio supremo de justicia, es decir, el debido proceso en su expresión desde el método jurístico dikelógico sobrepasa la diferenciación entre proceso y procedimiento ${ }^{39}$ y sirve como expresión normativo-estructural-fundamental, en su faz

39 Cfr. GONZÁLEZ ÁLVAREZ, Roberto, Neoprocesalismo... Op cit., c. VII, sc. I, 4. 
valorativa, del derecho de acción como derecho a la justicia; y en su expresión desde el método jurístico sociológico, se encuadra en la naturaleza del proceso diferenciada del procedimiento, como estricta expresión principial procesal fundamental, pues su universo de aplicación es el del derecho procesal.

Si se mencionan los sentidos del debido proceso (amplio y estricto) es por mera claridad estructural principial, porque queda fijo que el debido proceso es uno solo y su única naturaleza de garantía habla ya, de por sí, todo lo que corresponde entender sobre él. Ahora, su sentido amplio favorece su proyección en la jurística dikelógica y su sentido estricto en la jurística sociológica, por lo demás, no hay un alto grado de utilidad en clasificar el debido proceso, mucho menos cuando esta garantía asiste a diversos ámbitos (extra)procesales, de manera que se propende a interpretar, o peor, clasificar, diversos "debidos procesos" (v.gr., legislativo, administrativo, constitucional, penal, civil, laboral, etcétera), lo que podría traducirse en el ámbito procesal en la desalineación estructural del debido proceso, como si fuera garantía de un derecho de acción también pasible de clasificación (v.gr., penal, civil, laboral, agrario, constitucional, etcétera). Hablar de un debido proceso administrativo, constitucional, civil, etcétera, solo tendrá utilidad en la medida en que con ello se quiera significar el contenido del debido proceso en relación a la materia procesal en que se ve fluctuar, nada más.

El escenario en que vive el debido proceso es propio del Estado democrático de derecho, en el que si bien el poder fluye a través de procedimientos, éstos tienen un límite que los encausa en legitimidad que es el debido proceso. En consecuencia, el poder se ejerce de acuerdo a los debidos procesos previstos en la Constitución o establecidos en ley ${ }^{40}$, lo que significa que el despliegue de poder se limita a respetar los condicionamientos del debido proceso, que no es sino el respeto a los derechos fundamentales y a sus garantías correlativas que de alguna manera tengan que ver con un obrar legislativo, administrativo o inter privatos, es decir, con un procedimiento implicado en su realización, lo que resulta más claro cuando se trata del proceso. Si se tiene en cuenta que el derecho de participación democrática tiene entre sus contenidos el derecho a la corrección del obrar estatal, es fácil entender que el debido proceso, y sus contenidos como garantías vinculadas a los referidos derechos, participan de todas las actuaciones públicas, a las que se suman las inter privatos.

Para esclarecer la vinculación entre debido proceso, democracia y derechos fundamentales, se debe tomar en cuenta que el derecho de participación democrática, o de obrar ciudadano en la democracia constitucional, enlaza estructuralmente la garantía de debido proceso, en tanto comprende la democracia sustancial no solo atada a los derechos fundamentales, sino, en igual medida, a sus garantías 
correlativas. Esto denota la democracia insertada en la Constitución ${ }^{41}$, es decir, un conjunto de principios fundamentales, reglas materiales y reglas formales que programan la vida social y la función estatal en ella, desde el principio supremo de justicia arraigado en los derechos fundamentales o en esa sustancialidad democrática que brota de la titularidad de éstos en "todos nosotros".

La sustancialidad constitucional del debido proceso, encaja en el principio supremo de justicia antes que en el principio democrático, en la medida en que la democracia fluye de la libertad, dignidad e igualdad ${ }^{42}$ que explican la justicia como principio supremo, según el cual se debe asegurar a "cada uno" -entiéndase a "todos" - una esfera de libertad, dignidad e igualdad. Esto determina que la democracia procura el respeto de los principios fundamentales con claras consecuencias, como la proscripción de las desigualdades, el favorecimiento de paz y armonía sociales, etcétera.

Esto último importa sobremanera, porque se traduce en que en el constitucionalismo democrático, aunque con severas críticas ${ }^{43}$, se determina que ese "todos" -entiéndase mayoría democrática- no puede decidir sobre todo -"territorio inviolable" ${ }^{44} \mathrm{o}$ "coto vedado" ${ }^{45} \mathrm{y}$ "esfera de lo indecidible" ${ }^{46}$-, sino solo sobre aquello que le corresponde decidir, de lo demás se ocupan los mecanismos contra mayori$\operatorname{tarios}^{47}$ (rigidez de la Constitución y justicia constitucional). Pero, democracia no solo es decisión, sino también participación formal en el procedimiento o proceso, y en ello también funciona el "todos", en la medida en que si tan solo uno de los individuos que conforma el total ("todos") tiene vetada la titularidad del derecho de participación (democrática) -comprendida por derechos como los de acción, de defensa, de petición o a leyes válidas ${ }^{48}$ - y de su garantía correlativa -debido

${ }^{41}$ Cfr. GUASTINI, Riccardo, “¿Peculiaridades de la interpretación constitucional?”, en Pensar el derecho. Ensayos de teoría jurídica contemporánea, BONORINO RAMÍREZ, Pablo Raúl (Editor), Lima, ARA Editores, 2010, 81 y ss.

42 Cfr. GRINOVER, Ada Pelegrini, A garantia constitucional do direito de ação e sua relevâcia no processo civil, São Paulo, Revista dos Tribunais, 1972, p. 14.

43 Cfr. BAYÓN, Juan Carlos, Derechos, democracia y constitución, en AA. VV., Neoconstitucionalismo(s), edición de Miguel Carbonell, Madrid, Trotta, 2009, pp. 211 y ss.

44 Cfr. BOBBIO, Norberto, Teoría general de la política, Madrid, Trotta, 1981, pp. 478 y ss.

45 Cfr. GARZÓN VALDÉZ, Ernesto, Derecho, ética y política, Madrid, Centro de Estudios Constitucionales, 1993, pp. 631 ss.

46 Cfr. FERRAJOLI, Luigi, "La esfera de lo indecidible y la división de poderes", en Estudios Constitucionales, Centro de Estudios Constitucionales de Chile, Universidad de Talca, año 6, n. 1, 2008, pp. 337; Principia Iuris. Teoría del derecho y de la democracia. Traducción de Perfecto Andrés Ibáñez; Luis Prieto Sanchís.; Marina Gascón Abellán; Alfonso Ruiz Miguel; Juan Carlos Bayón, Madrid, Trotta, v. 1, 2011, pp. 773 y ss.; BAYón, Juan Carlos, Op. cit., pp. 428 y ss.

47 Cfr. Ibídem., 413 y s.

48 Cfr. GAMA, Lidia Elizabeth Peñaloza Jaramillo, Op. cit., p. 22. 
proceso-, éstos no pueden ser reconocidos como fundamentales, sino como ajenos a la democracia constitucional. De manera que no habiendo individuo alguno que no tenga atribuida la titularidad de ese derecho y de su garantía correlativa, éstos -derecho y garantía- son a no dudarlo fundamentales pero, atención, en el contexto democrático constitucional, es decir, con participación en la construcción democrática del Estado de derecho.

Se ha esclarecido ${ }^{49}$ que las normas constitucionales formales (políticas o procedimentales), garantizan la dimensión formal de la democracia política (el quien y el cómo de las decisiones); y las normas constitucionales sustanciales, garantizan la dimensión material de la democracia sustancial (el qué de las decisiones). La democracia formal está orientada, vía derechos de autonomía, por quién y cómo se manda; y la democracia sustancial está orientada, vía derechos fundamentales de condicionamiento negativo (lo indecidible) y positivo (lo indecidible que no), por qué se manda.

Si el debido proceso es parte de la democracia en la Constitución, su eje gravitatorio funcional, no de fundamento o naturaleza, está en la expresión formal u objetiva de la democracia, no en la sustantiva (subjetiva o material), toda vez que en ello tiene injerencia el principio de proporcionalidad, y para asentir lo contrario habría que convivir con el substantive due process que debe, de una vez, desaparecer del sistema del civil law. El despliegue de la democracia se realiza a través del debido proceso, pues sin éste aquélla no tendría viabilidad. Esto es pues, qué duda cabe, garantía del derecho a la participación democrática y, en ello, de la democracia misma. Entonces, si es garantía, de más está remarcar su connotación material, claro está, material procesal, o mejor, procesal fundamental, porque definitivamente la tiene; resulta, entonces, contraproducente entender un "debido proceso formal", reduciéndolo a la perspectiva de garantías "estrictamente procesales", como si éstas no pusieran en juego la libertad, igualdad y dignidad del justiciable en escenario procesal, pues aun cuando se trata de principios de eficiencia o técnicos, siguen siendo principios (estrictamente garantías) y, por tanto, materiales, sustantivos

49 Cfr. FERRAJOLI, Luigi, "La esfera de lo indecidible y la división de poderes", en Estudios Constitucionales, Centro de Estudios Constitucionales de Chile, Universidad de Talca, año 6, n. 1, 2008, pp. 337 y ss.; Democracia y garantismo, edición de Miguel Carbonell, Madrid, Trotta, 2008, pp. 31 y ss.; SALAZAR UGARTE, Pedro, "Los límites al a mayoría y la metáfora del contrato social en la teoría democrática de Luigi Ferrajoli. Dos cuestiones controvertidas", en AA. VV., Garantismo. Estudios sobre el pensamiento de Luigi Ferrajoli, edición de Miguel Carbonell y Pedro Salazar, Madrid, Trotta, 2009, pp. 429 y ss.; CÓRDOVA VIANELLO, Lorenzo, "Constitucionalismo democrático y orden global en Luigi Ferrajoli», en Garantismo. Estudios sobre el pensamiento de Luigi Ferrajoli, edición de Miguel Carbonell y Pedro Salazar, Madrid, Trotta, 2009, pp. 447 y ss.; PRIETO SANCHÍS, Luis, "Principia iuris, una teoría del derecho no (neo) constitucionalista para el Estado constitucional”, en El canon neoconstitucional, CARBONELL, Miguel y GARCÍA JARAMILLO, Leonardo (Editores), Bogotá, Universidad Externado de Colombia, 2010, pp. 275 y ss. 
o sustanciales. Por eso resulta poco útil advertir, en el proceso, una "dimensión formal" como contraparte de otra "dimensión material"50.

$\mathrm{Al}$ igual que la "democracia constitucional" ${ }^{1}$, el "Estado constitucional de derecho" 52 exige determinar, ante todo, cuál es el sentido que le corresponde tener de la Constitución ${ }^{53}$, lo que trae como consecuencia hablar, en ambos casos, de una Constitución sustantiva, rígida, limitadora del legislador ${ }^{54} \mathrm{o}$, mejor, del poder público, es decir, una Constitución explicada por el constitucionalismo actual, una "Constitución constitucionalizante" del derecho, entendida y explicada por el (neo) constitucionalismo.

No se debe olvidar, que el debido proceso es parte estructural del principio de acción, de manera que cuando se dice que la acción es principio de cierre del ordenamiento, se considera la composición del debido proceso como parte de la estructura normativa del principio de acción. Sin la participación del debido proceso, como garantía del derecho de acción, la estructura principial que conforma no podría llamarse de cierre, claro está, lo propio ocurre con la garantía de tutela jurisdiccional, ésta también determina esa condición de cierre. En fin, se la acción es principio de cierre o extensión del principio supremo de justicia, es por su contenido de garantías, y entre ellas el debido proceso es medular, porque posibilita al individuo afirmar, argumentar, probar, contradecir en los procedimientos del Estado democrático de derecho.

La democracia permite que los ciudadanos se expresen o discursen racionalmente ${ }^{55}$, directa o indirectamente pero siempre en forma activa en los diversos despliegues procedimentales, por los que se fabrica y aplica una ley, con la finalidad de que sus intereses no sean aplastados, es decir, promoviendo que esos intereses fluyan coherentemente en la vida social, defendiéndolos, restableciéndolos, o mejor, procurando su tutela en democracia.

La articulación del debido proceso con la democracia está en la base de ésta, porque el debido proceso, en la composición estructural del principio de acción, permite que todos los principios fundamentales (de la libertad, de la igualdad, políticos y sociales) cohesionen en el Estado democrático de derecho.

50 Sobre la dimensión substantiva del debido proceso Cfr. SILVEIRA, Paulo Fernando, Op. cit., pp. 243 y ss., 417 y ss.

51 Cfr. GONZÁlEZ ÁlVAREZ, Roberto, Neoprocesalismo... Op. cit., c. II, sc. III, 2.

52 Cfr. Ibídem, c. II, sc. III, 3.

53 Cfr. AGUILÓ REGLA, Josep, “Sobre la Constitución del Estado constitucional”, en El derecho en acción. Ensayos sobre interpretación y aplicación del derecho, BONORINO RAMÍREZ, Pablo Raúl (Editor), Lima, ARA Editores, 2010, pp. 83 y ss.

54 Cfr. FIORAVANTI, Maurizio, Constitución. De la antigüedad a nuestros días. Traducción de M. Martínez Neira, Madrid, Trotta, 2001, pp. 161 y ss.

55 Cfr. HABERMÁS, Jürgen, Facticidad y validez. Sobre el derecho y el Estado democrático de derecho en términos de teoría del discurso. Traducción de M. Jiménez Redondo, Madrid, Trotta, 1998, p. 172. 


\section{LA gARANTía del dereCho A LA EFICIENCIA DEL PROCESO: EL DEBIDO PROCESO (EN SENTIDO ESTRICTO)}

El debido proceso tiene naturaleza fundamental, sea en su sentido amplio o estricto, pues es garantía del derecho de acción, es decir, es pieza componente de la estructura normativa del principio de acción, en tal condición no puede tener naturaleza procesal, sino sustancial procesal, o mejor, procesal fundamental. Este es otro aspecto que evidencia que la diferenciación entre substantive due process y procedural due process, es una aporía más que el common law genera cuando uno de sus componentes es importado en el civil law.

El debido proceso, en sentido estricto, se circunscribe a la eficiencia procesal, por eso expone su contenido, que es correlativo a los derechos comprendidos en el derecho de acción, en tanto éste es abordado por el método jurístico sociológico.

La jurisprudencia constitucional se ha esforzado en diferenciar el debido proceso constitucional del debido proceso legal, distinción que tiene una lectura paralela; por un lado es una epifanía de la distinción entre substantive due process y procedural due process; y por otro lado, es la usurpación del contenido de la garantía de tutela jurisdiccional para mostrarlo como contenido de la garantía de debido proceso.

Esa lectura dual realizada por la jurisprudencia referida, es consecuencia de no lograr advertir que la interacción principial del contenido del debido proceso es intensa en cada caso concreto, y que su contenido no se determina por intuición, sino por la configuración estructural del derecho de acción; de modo tal que, la efectividad de la acción, que la proyecta como derecho a la función jurisdiccional, enlaza la garantía de tutela jurisdiccional y su contenido, en cambio, la eficiencia de la acción, que la proyecta como derecho al proceso, enlaza la garantía de debido proceso y, claro está, su contenido.

Consecuentemente, la idea de que puede diferenciarse un debido proceso constitucional de otro legal no solo atenta (i) el desarrollo neoconstitucional de los principios (en tanto éstos tienden a una optimización en su aplicación, es más, que su interpretación, contenido y aplicación se maximizan in casu), (ii) la estructura (integrativista trialista) del derecho de acción y de sus garantías y (iii) la propia interacción principial, sino, algo peor, vuelve a traer a escena el sentido del debido proceso que debe proscribirse del civil law: el substantive due process.

¿Qué significa la interacción principial intensa del contenido del debido proceso? Significa la aplicación ponderativa de los contenidos de la garantía de debido proceso que, como se sabe, son otras garantías, de naturaleza técnica o de eficiencia (propias del orden del método jurístico sociológico), pero que no dejan de ser principios, propiamente garantías. Lo que significa que aun cuando son principios, que están involucrados en meras "anomalías" o "simples irregularidades procesales" (por negligencia o actuar deliberado), son portadores de fundamentalidad, y el 
hecho de que no salten al plano del proceso constitucional es porque precisamente la interacción entre ellos hace que se reduzcan a los confines del proceso, es pues, una interacción latente e intensa; de manera que, los partícipes del proceso muchas veces no la perciben, porque se trata de garantías técnicas, es decir, de principios de eficiencia; ahora, no se debe dejar de percibir que también en el proceso constitucional se evidencia esa interacción.

El asunto no gravita en advertir que se trata de "infracciones menores" que "no trascienden al proceso", "no resultan incompatibles con la Constitución" y, por tanto, "no tienen relevancia constitucional" ${ }^{56}$, sino que se trata de infracciones constitucionales, que se conjuran en el proceso, en la instancia de origen o en la superior, resultando constitucionales, es decir, no pierden su relevancia constitucional porque obedecen a una interacción principial intensa. Frente a cualquier circunstancia, el debido proceso es una garantía del derecho de acción, por tanto de la libertad y dignidad, algo más, es límite del poder en las actuaciones jurisdiccionales.

Esta interacción, que no es débil, se puede entender de mejor manera con el ejemplo siguiente: realizada en forma defectuosa la notificación de la demanda al demandado, ocurre que éste contesta la demanda en forma oportuna; en este caso la notificación defectuosa de la demanda vulnera, en el plano de la eficiencia del derecho de acción, el derecho del demandado a actos procesales válidos (frente a la invalidez de la notificación), consecuentemente activa la garantía de legalidad de los actos procesales, pero también quedaron encendidas las garantías de finalidad y convalidación; de manera que, entre estas garantías, la interacción -nunca colisión- que las integra determina, in casu, que no es parte del contenido de la garantía de legalidad la notificación que cumplió su finalidad, pese a estar defectuosamente realizada, y que no obstaculizó la contestación oportuna a la demanda, consecuentemente, es contenido del principio (propiamente garantía) de finalidad, el conocimiento oportuno que el demandado asumió de la demanda aún cuando ésta fue defectuosamente notificada, de igual modo, es contenido de la garantía de convalidación la contestación oportuna de la demanda por el demandado aún cuando ésta se le haya notificado defectuosamente.

Ese ejemplo también puede entenderse en el plano de la efectividad del derecho de acción, es decir, poniendo en escena la vulneración del derecho de defensa y la activación de las garantías contenidas en la garantía de tutela jurisdiccional, particularmente de la garantía de emplazamiento válido, intensamente interactuantes con las garantías del debido proceso, de manera que el resultado, in casu, comenzaría por determinar que no es parte del contenido de la garantía de emplazamiento válido la notificación defectuosa que cumplió la finalidad de dar a conocer la demanda, autoadmisorio y anexos al demandado...

56 Corte Constitucional (Colombia), sentencia T-461. 
Se trata a todas luces de la aplicación ponderativa (como equilibrio) de las garantías del debido proceso, claro está, se trata de una aplicación que las partes y el juez la entienden como resultado, aunque muchas veces no como procedimiento ponderativo, de manera que puede dar lugar a un pronunciamiento jurisdiccional motivado en la aplicación principial referida; pero, también puede pasar desapercibido, caso en el que se hace notar la intensidad de esa interacción principial.

Lo cierto es que aquí no debe dejarse de ver que los contenidos fundamentales están presentes e interactuantes en el proceso; no se trata, pues, de una "simple irregularidad procesal" que no delata inconstitucionalidad del proceso, ésta existió pero fue conjurada por la interacción intensa de las garantías del debido proceso.

Teniendo en cuenta lo dicho, y frente a que la jurisprudencia ${ }^{57}$ constitucional parte de la premisa de que no toda vulneración al contenido del debido proceso es susceptible de control de constitucionalidad, conviene esclarecer que según esa jurisprudencia la inconstitucionalidad de un proceso aparece solo si se vulnera el contenido esencial de algún derecho fundamental, pero no cuando se trata de anomalías o "simples irregularidades procesales", que gravitan en el contenido no esencial o adicional de los derechos fundamentales, que solo contravienen al orden legal pero no al constitucional. Entonces, siguiendo esa equivocada línea, el debido proceso constitucional sirve para retomar la constitucionalidad del proceso a través del proceso constitucional y el debido proceso legal para conjurar la anomalía o irregularidad en la jurisdicción ordinaria a través de los medios de impugnación, solamente así se evitará que cualquier reclamación se pretenda configurar como un tema constitucional. Con otras palabras, solo hay debido proceso constitucional en/con/por el proceso constitucional y solo hay debido proceso legal en la jurisdicción ordinaria, o sea, no hay debido proceso constitucional en el proceso de la jurisdicción ordinaria, y no hay debido proceso legal en el proceso de la jurisdicción constitucional.

En consecuencia, caen de maduras las preguntas siguientes: ¿puede el debido proceso clasificarse por la materia a que obedece el proceso?, ¿no hay debido proceso legal en el trámite previsto en el proceso constitucional?, ¿los jueces ordinarios no tutelan los derechos procesales fundamentales? Y, finalmente, ¿asoma nuevamente el anatema del fondo y forma?, es decir, ¿debido proceso constitucional es debido proceso sustancial o material y debido proceso legal es debido proceso formal o procesal?

Antes de dar respuesta conviene señalar que el error de la diferenciación jurisprudencial anotada asume origen en la deficiente concepción de la naturaleza, contenido y estructura de los derechos fundamentales; pues, en esta lamentable línea jurisprudencial se consienten las teorías de los derechos fundamentales

57 Tribunal Constitucional (Perú), sentencia $N^{\circ} 8453-2005-P H C / T C$, F. J. 7; expediente $N^{\circ} 1014-$ 2007-PHC/TC, sentencia de 5 de abril de 2007. 
indistintamente entendidos como garantías ${ }^{58}$, del núcleo duro del contenido fundamental ${ }^{59}$ y de la colisión de derechos fundamentales ${ }^{60}$. Se descuida (i) que la tesis del núcleo duro del contenido de los derechos fundamentales es inconstitucional, pues el contenido de los principios fundamentales es, todo él, fundamental y punto; (ii) que el debido proceso no es un derecho, sino una garantía, por tanto, el contenido fundamental vulnerado prima facie es el del derecho de acción, claro está, a través de su propio contenido; y (iii) que los principios fundamentales, también en el plano del método jurístico sociológico, es decir, tratándose de la interacción de principios de eficiencia o técnicos, mal vistos en una simple "anomalía" o "irregularidad procesal", se aplican por ponderación, eso sí, como equilibrio ${ }^{61}$ y no como pesaje ${ }^{62}$.

Ahora sí, absolviendo la primera pregunta, ¿puede el debido proceso clasificarse por la materia a que obedece el proceso?, es evidente que no, porque lo mismo ocurriría, necesariamente, con el derecho de acción, y nada más lejano de su naturaleza que el diferenciarse en sí mismo por la materia a la que asiste el proceso, es decir, si no hay la posibilidad de estudiar el derecho de acción constitucional, frente al derecho de acción "infraconstitucional", tampoco habrá la posibilidad de entender válidamente el debido proceso constitucional frente al debido proceso legal.

¿No hay debido proceso legal en el trámite previsto en el proceso constitucional? La pregunta encierra una falacia. El proceso constitucional no deja de ser proceso, y los principios (derechos y garantías) fluctúan en él en la misma forma en que lo hacen en cualquier otro proceso. Entonces, quienes siguen la idea de diferenciar los debidos procesos constitucional y legal no podrían negar que hay debido proceso legal en el debido proceso constitucional.

¿Los jueces ordinarios no tutelan los derechos procesales fundamentales? Desde la perspectiva del "debido proceso constitucional" pareciera asentirse la pregunta; pero para ello, habría que hacer a un lado la naturaleza principial del derecho de acción, de su garantía de debido proceso y de sus respectivos y correlativos contenidos, de manera que solo así se dejaría de entender su interacción intensa en el proceso, sea cual fuese la materia a la que asista. Definitivamente, los jueces ordinarios también tutelan los derechos fundamentales, sus garantías correlativas y sus respectivos contenidos. El debido proceso, como el derecho de acción, es uno solo no tiene por qué dividirse o clasificarse por la materia procesal, peor aún, por la ilusoria autoatribución excluyente de tutela de derechos fundamentales. Se confunde paladinamente la naturaleza y sentido de las pretensiones constitucionales (mal llamadas garantías) con la interacción principial procesal fundamental.

\footnotetext{
58 Cfr. GONZÁLEZ ÁLVAREZ, Roberto, Neoprocesalismo... Op. cit., c. II, sc. III, 6.3.

59 Cfr. Ibídem, c. II, sc. IV, 3.2, 3.3.

60 Cfr. Ibidem, c. II, sc. IV, 3.4.

61 Cfr. Ibidem, c. III, sc. I, 7.3.

62 Cfr. Ibídem, c. III, sc. I, 7.2.
} 
Finalmente, ¿asoma nuevamente el anatema del fondo y forma?, es decir, ¿debido proceso constitucional es debido proceso sustancial o material y debido proceso legal es debido proceso formal o procesal? Las preguntas podrían asistirse del criterio de que el debido proceso permite un control "meramente procesal" o formal y también un control material o sustancial ${ }^{63}$, caracterizándose este último por ser de proporcionalidad y controlar las decisiones y sus efectos ${ }^{64}$, en la idea de que lo "debido" a más de referirse al "cómo se ha de actuar" también se refiere a "qué contenidos son válidos o constitucionales", como si lo fundamental pudiera comprenderse en una parte material y en otra formal o "meramente procesal", tal vez ello se divise con claridad de lo constitucional pero no de lo fundamental, axiológico o dogmático de la Constitución, que es donde vive el debido proceso, no en parte sino todo él. Lo fundamental siempre es material o sustancial y lo procesal no siempre es formal, de manera que lo procesal fundamental no implica, en lo absoluto, condición formal.

Siendo así, no se puede sino reconocer que la maldición de entender el derecho desde el fondo y la forma ${ }^{65}$ está de nuevo en juego, por eso se olvida que tratándose la naturaleza del debido proceso, de ser una garantía, su despliegue siempre será fundamental y aún cuando se vea en un escenario de actuación procesal, el compromiso que tiene frente al contenido del derecho de acción no lo deja de mostrar fundamental. No es acaso una realidad evidente que el proceso no solamente es lo procesal, sino también lo procesal fundamental en estricta convivencia, de modo tal que una actuación indebida o irregular compromete el derecho de acción, propiamente algún ámbito de su contenido y, claro está, también el de sus garantías correlativas. Entonces, que la interacción principial no sea desde la pretensión constitucional, no significa que no sea intensa en el proceso, o mejor, no significa que deje de ser fundamental. Por eso no corresponde hacer una distinción entre debido proceso sustancial y debido proceso procesal, es ya una herencia que merece dejarla pasar, para confinarla al mismo olvido al que hemos arrojado el substantive due process en el civil law.

Pero esto no queda ahí, el problema del fondo y forma en el debido proceso tiene una manifestación aún más vehemente, que es la del proceso equitativo, de la técnica y ética del debido proceso. Se dice ${ }^{66}$ que el debido proceso tiene un perfil técnico y otro ético; el primero implica la funcionalidad intuitiva del proceso justo,

63 Sobre el debido proceso como garantía objetiva (formal) y subjetiva (sustancial) Cfr. ROTA, Fabio, Op. cit., pp. 71 y s.; CAVALLINI, Daniela, "Il giusto processo tra diritto positivo e deontologia giudiziaria”, en Giusto processo? Introduzione di diritto fondamentali dei cittadini o creazione di canoni processuali di rango costituzionale? Scritti in onore di Giuseppe Di Federico, al cuidado de Carlo Guarnieri y Francesca Zannotti, Padua, Cedam, 2006, pp. 219 y ss.

64 Tribunal Constitucional (Perú), expediente $\mathrm{N}^{\circ}$ 1209-2006-PA/TC.

65 Cfr. NIEVA FENOLL, Jordi, Jurisdicción y proceso, Madrid, Marcial Pons, 2009, pp. 16 y s.

66 Cfr. COMOGLIO, Luigi Paolo, Op. cit., pp. 2 y ss., 151 y ss. 
debido o equitativo (equo), suficiente para la justicia procesal; y el segundo, se traduce en el absoluto respeto de la persona y de sus derechos esenciales. Acaso la interacción intensa de los principios procesales fundamentales, vista en la resolución de problemas intuitivamente, no conlleva el respeto y tutela de los derechos fundamentales, si son estos mismos en sus expresiones técnicas, como contenidos del derecho de acción y de sus garantías correlativas, los que están obrando en proceso. Si la técnica es lo procesal y la ética es lo fundamental, no es acaso una proterva epifanía más del fondo y forma en el debido proceso. Proceso debido o justo no es el que resulta regular en el plano formal, proceso justo es el que se desarrolla en los parámetros de la norma constitucional ${ }^{67}$, o mejor, en lo principial ius-fundamental de la Constitución.

\section{Debido PROCESO: DEL DERECHO A LAS MíNIMAS garantías a LA GARANTÍA DE MÁXIMOS DERECHOS}

En la ruta del procedural due process ${ }^{68}$, un proceso en el que se observe la información cierta concerniente a un hecho (notice) o el derecho de audiencia (hearing) ${ }^{69}$ a favor del justiciable, se considera debido (due) o justo (fair), puesto que de tales exigencias, consideradas como mínimos procesales, dependía la violación o no de la justicia procesal (procedural fairness). Ese mínimo, que propiamente significaba un mínimo contenido de hearing, o de algunas manifestaciones de defensa en juicio, es expresión de tutela de un interés comprendido en la propiedad, la libertad y la vida ${ }^{70}$, pues solo así importa la aplicación del procedural fairness, y solo así se entendía viable el due process.

Si algo quedó muy marcado en el civil law sobre las exigencias con que funciona el due process es que son consideradas en conjunto como "un mínimo", es decir, elementos sumamente imprescindibles para que un proceso sea debido. En consecuencia, se trata de un derecho -recuérdese que en esta perspectiva extranjera el debido proceso es un derecho- de mínimos contenidos (propiedad, libertad y vida) y, por tanto, de mínimas garantías.

Frente a esto, la jurisprudencia no demoró mucho en hipertrofiar ese mínimo que de tal ya nada tenía, más aún, cuando fue sobrepasada de sus cánones originarios (propiedad, libertad y vida) y, sin embargo, aun proliferan definiciones, en la doctrina y jurisprudencia, que apelan a entender el debido proceso como el derecho a un mínimo de garantías.

\footnotetext{
67 Cfr. TROCKER, Nicolò, Op. cit., p. 386.

68 Sobre la evolución del debido proceso procesal Cfr. Silveira, Paulo Fernando, Op. cit., 309 y ss.

69 Cfr. CASTRO, Carlos Roberto Siqueira, Op. cit., p. 31.

70 Cfr. DE BERNARDIS, Luis Marcelo, La garantía procesal del debido proceso, Lima, Cultural Cuzco, 1995, p. 280.
} 
Pero la idea de mínimos también estuvo presente en los condicionamientos procesales, es decir, en "mínimos procesales" que determinan la protección del debido proceso procesal; si esto es así, si no existe una transgresión significativa, o mínimamente significativa, a los derechos de propiedad, libertad y a la vida no tiene por qué observarse un debido proceso procesal, con lo que éste ya no se considera un derecho en sí mismo, sino solo por la vulneración de aquéllos; se trata, pues, de configurar el debido proceso como instrumento de protección de derechos. El olfato del common law norteamericano atisba a ciegas la real naturaleza del debido proceso, la de ser una garantía. Esto se confirma cuando se constata ${ }^{71}$ que es poco probable que la Suprema Corte reconozca (in)directamente el derecho a un debido proceso en sí mismo y no como instrumento de tutela de derechos.

Aun cuando ni los legisladores ni los jueces del civil law consideran lo precedente, hay en ellos la exigencia de una nueva perspectiva sobre los principios jurídicos entendidos como derechos, garantías y las normas que los consagran. Se trata de la fuerza del neoconstitucionalismo, que entiende los principios fundamentales -el debido proceso siendo garantía lo es- maximizados en su contenido, interpretación y aplicación, lo que determina que el debido proceso es garantía fundamental de contenidos máximos, que en su interpretación se optimizan y en su aplicación se delimitan. En fin, el debido proceso, desde la perspectiva del neoconstitucionalismo, es una garantía de máximos contenidos llevados al límite por la ponderación. Consecuentemente, resulta equivocada la idea de "mínimos constitucionales" o "bases constitucionales mínimas"72 del debido proceso, porque sencillamente si es un principio fundamental sus bases, contenidos, corpus, interpretaciones y aplicación, son máximos.

Con el primer constitucionalismo, el surgido a partir de la Magna Charta de 1215, el debido proceso se identificó con las garantías mínimas de las que brotó, es decir, la configuración del due process of law es la que remite a la perspectiva de los mínimos (contenidos y exigencias para su vulneración) en el debido proceso y, a no dudarlo, fue así que se tornó en matriz cultural ${ }^{73}$ que luego dio espacio a la moderna historia constitucional europea. Con el segundo constitucionalismo, que vino con la segunda posguerra mundial, el debido proceso se identificó desde las garantías internacionales del proceso equitativo ("processo equo", "procès équitable", "faires Verfabren") 74 . Actualmente, con el neoconstitucionalismo, el debido proceso se entiende en el esquema normativo principial, la democracia constitucional, el

\footnotetext{
$71 \quad$ Ibídem., p. 197.

72 Cfr. MORELLO, Augusto Mario y COMOGLIO, Luigi Paolo, "Bases constitucionales mínimas del proceso civil justo para América Latina”, en COMOGLIO, Luigi Paolo, Etica e tecnica del "giusto processo", Turín, Giappichelli, 2004, pp. 416 y ss.

73 Cfr. TROCKER, Nicolò, Op. cit., p. 383.

74 Cfr. COMOGLIO, Luigi Paolo, Op. cit., pp. 39 y ss., 225 y ss.
} 
Estado democrático de derecho y, particularmente, la perspectiva garantista del derecho, por tanto, como garantía del derecho de acción, optimizable en su contenido y con máxima injerencia en el ordenamiento, en su aplicación en el obrar público y privado, en fin, en la vida social misma.

\section{DEBIDO PROCESO PROPORCIONAL}

El debido proceso proporcional ${ }^{75}$ es una concepción neoprocesal del debido proceso, es decir, encajada en el orden normativo de los principios comprendidos con una estructura (normativa) integral entre derechos y sus correlativas garantías; así, el derecho de acción tiene entre sus correlativas garantías las de tutela jurisdiccional y debido proceso, la primera es garantía del derecho de acción, como derecho a la tutela jurisdiccional (plano del método jurístico normológico); y la segunda, en sentido amplio, es garantía del derecho de acción como derecho a la justicia (plano del método jurístico dikelógico) y, en sentido estricto, es garantía del derecho de acción como derecho al proceso (plano del método jurístico sociológico). La conjunción estructural del derecho de acción con sus correlativas garantías se denomina principio de acción, en tanto esto no es óbice para denominar "principio" al derecho de acción (y a cualquiera de los derechos fundamentales contenidos en él) o a cualquiera de sus garantías, pues recuérdese que neoconstitucionalmente los principios son los derechos, sus garantías y las normas que los consagran, todos fundamentales. Si bien, el debido proceso, tiene una composición trialista ésta es integrativista, es decir, no presume separación alguna de su estructura pues obra, toda ella, en cada manifestación funcional del principio de acción, con toda su composición.

El principio, propiamente garantía, de debido proceso proporcional, como se puede ver, participa de la estructura integrativista trialista del objeto jurídico, transitando por el escenario neoconstitucional en tanto se solventa en la democracia constitucional, ergo, en el Estado democrático de derecho, por lo que, su naturaleza fundamental no es oscilante sino permanente, de manera que no se puede identificar el debido proceso como estructura meramente formal, sino siempre procesal fundamental; en consecuencia, el desdoblamiento que nace de la perspectiva del common law sobre el debido proceso, en tanto se le asigna una faz sustantiva (substantive due process) y otra procesal (procedural due process), es absolutamente intolerable en la concepción neoprocesal del debido proceso.

Si el debido proceso es siempre procesal fundamental, su aplicación siempre será ponderativa, sea por interacción intensa o por aplicación de todo el contenido del principio de proporcionalidad, soportado en el criterio de razonabilidad. En el primer caso, que es el de actuación de la garantía de debido proceso por interacción principial intensa, los principios obran espontáneamente, motu proprio o in

75 Cfr. CAMPOS, Amini Haddad, O devido processo proporcional, São Paulo, Lejus, 2001. 
natura, de manera que el aplicador no requiere desplegar el contenido del principio de proporcionalidad y en él el criterio de razonabilidad, particularmente debido a que se trata de manifestaciones principiales de eficiencia es decir de principios técnicos procesales, caracterizados porque son binarios o dicotómicos, que no por ello dejan de comprometer contenidos fundamentales. En el segundo caso, que es el de actuación forzosa (motivada con razonabilidad) de los principios, éstos conjuran la arbitrariedad por declaración jurisdiccional expresa, lo que bien puede ocurrir en el proceso ordinario o en el proceso constitucional, sin que ello justifique una diferenciación entre debido proceso constitucional o debido proceso legal, que es altamente innecesaria e impertinente frente a la perpetua naturaleza procesal fundamental del debido proceso. El principio de proporcionalidad es fundamento de la efectividad procesal.

En cualquiera de las situaciones en que obra la garantía de debido proceso, no deja de ser proporcional, no deja de ser un debido proceso proporcional.

\section{Conclusión}

El principio fundamental de acción es el nuevo paradigma del derecho procesal, los cambios espistemológicos (métodos jurísticos del integrativismo trialista) y cognitivos (neoconstitucionalismo) que lo asumen como tal, son también los que presentan una nueva comprensión de la garantía de debido proceso.

La presencia neoprocesal del principio de proporcionalidad evidencia la necesidad de desterrar el substantive due process, pues usurpa su lugar con un consecuente sobredimensionamiento de la razonabilidad como principio, cuando no es más que criterio hermenéutico que discurre por los interiores de la proporcionalidad. En suma, el derecho procesal actual distingue claramente las exigencias de sus entrañas sistémicas, por eso una pieza tan poco clara y ajena a su genética, como el substantive due process, no solo rechina en su potente máquina, sino debe ser reemplazada por una que calce sistémicamente: el principio de proporcionalidad.

No existe un debido proceso "sustancial" ni otro "procesal". El debido proceso es, nada más ni nada menos, procesal fundamental, por eso no puede acogerse la perniciosa comprensión de lo procesal como lo formal, en contraposición a lo sustancial, esa postura sobre el fondo y la forma se traduce en la idea, que no deja de ser nociva, de un debido proceso sustantivo y otro procesal.

El compromiso de la fundamentalidad del debido proceso es permanente y se evidencia con latencia en las situaciones intraproceso de interacción principial técnica o de eficiencia (interacción intensa), es decir, en la interacción de las manifestaciones de su propio contenido; y con patencia, en las situaciones intra/ extraproceso en que sus contenidos interactúan con los contenidos de otras garantías de otros derechos fundamentales. En el primer caso, se puede contemplar un debido proceso en sentido estricto, y en el segundo caso, un debido proceso en 
sentido amplio; pero para cualquier efecto, estos sentidos solo son de pedagogía de su entendimiento, pues en ningún caso significan un criterio clasificatorio dado que el debido proceso es uno solo.

Los contenidos del debido proceso son fundamentales, por tanto no pueden ser contenidos mínimos, sino son siempre máximos, en tanto esta maximización también comprende su interpretación y aplicación a través del principio de proporcionalidad, el cual, actúa en forma espontánea en la interacción latente (o intensa, que compromete solo el contenido de proporcionalidad en sentido estricto o ponderación, como resultado no como aplicación) de los contenidos del debido proceso; y en forma forzosa en casos de interacción patente de los contenidos del debido proceso, es decir, fluctúa inherente al obrar del debido proceso (que compromete los tres sub principios del principio de proporcionalidad, como interpretación y aplicación), razón por la que no queda sino hablar de debido proceso proporcional. 
